\title{
UNLEARNING IN ORGANIZATIONS: UNDERSTANDING AND RETHINKING THE WAY ORGANIZATIONS LEARN AND CHANGE
}

\author{
DOI: 10.17261/Pressacademia.2019.1062 \\ PAP- V.9-2019(9)-p.43-47
}

\section{Tolga Ege ${ }^{1}$, Ayla Esen ${ }^{2}$, Ozen Asik $^{3}$}

${ }^{1}$ Presidency of the Republic of Turkey, Presidency of Strategy and Budget, Ankara, Turkey

tolga.ege@sbb.gov.tr, ORCID: 0000-0003-0097-7789

${ }^{2}$ Altinbas University, School of Business Administration, Istanbul, Turkey.

ayla.esen@altinbas.edu.tr, ORCID: 0000-0002-6937-3476

${ }^{3}$ Fairleigh Dickinson University, Department of Management, Vancouver, BC, Canada.

o_dizdar@fdu.edu , ORCID: 0000-0003-3086-7214

\section{To cite this document}

Ege, T., Esen, A., Asik O., (2019). Unlearning in organizations: understanding and rethinking the way organizations learn and change. PressAcademia Procedia (PAP), V.9, p.43-47

Permanent link to this document: http://doi.org/10.17261/Pressacademia.2019.1062

Copyright: Published by PressAcademia and limited licenced re-use rights only.

\begin{abstract}
Purpose- This paper aims to portray the overall picture in the relevant literature regarding unlearning and intends to emphasize its role both in organizational learning and organizational change processes. Through a framework, it aims to figure out how unlearning should be considered in organizations, especially in management practices, and propose a future reseach agenda to develop an advanced field.

Methodology- The paper summarizes the relevant literature from a critical perspective; it reviews definitions and aims to clarify what unlearning means for organizations at individual, group and organizational levels and argues how the concept of unlearning has been mentioned in models, frameworks and ideas in relation to organizational change, organizational learning and learning organizations. It provides range of definitions to develop the limited understanding of unlearning in management practices, and examines models, frameworks and ideas to clarify the confusions in literature.

Findings- Literature on organizational learning and change has elaborated on the idea of unlearning from different perspectives, highlighted its importance and attempted to clarify its meaning and processes in organizations at various levels. However, limited research has been carried out where the process of unlearning has been reflected in different organizational settings, and relatedly, fewer seminal works, compared to organizational learning and organizational change ones, remained acknowledged.

Conclusion- Current knowledge in organizational studies restricts a detailed understanding of unlearning and lack of empirical studies leaves the territory under-researched and blurred. Through the framework proposed above and future research in parallel, we aim to capture a widened understanding of unlearning in literature and intend to construct a new perspective in management practices, mainly in organizational learning and change processes.
\end{abstract}

Keywords: Unlearning, unlearning in organizations, organizational change, organizational learning, learning organization JEL Codes: L20, M10, M19

\section{INTRODUCTION}

There has been an increased interest regarding continuous development in organizations. This trend has necessitated continuous learning and change in work settings both at individual and organizational levels. Accordingly, scholars and practitioners have proposed enormous amount of models, frameworks and ideas in response. However, while there have been widely accepted ones, these models have also been criticized by being general, broad, repetitive and sometimes contextual, that they cannot be applied properly to organizations in a wider sense. Besides, they have been considered as lacking the fundamental idea that 'understanding environments that change requires tearing down obsolete mental maps and starting anew' (Hedberg, 1981:4). In this sense, the literature provided new understandings, offerings and alternative solutions, in which 'unlearning' has been one of them, as a different perspective, idea or as an unconventional path within the domain of organizational learning and organizational change. (Easterby-Smith, 1997; Easterby-Smith and Lyles, 2011; Fiol and Lyles, 1985; Hedberg, 1981; Nystrom and Starbuck, 1984). 
Accordingly, studies have elaborated on the idea of unlearning from different perspectives (e.g. Akgün et al., 2007; Becker, 2018; CegarraNavarro and Wensley, 2019; Gustavsson, 2001; Klammer et al., 2019; Sinkula, 2002; Starbuck, 2017; Tsang and Zahra, 2008). They highlighted the importance of the notion and attempted to clarify its meaning and processes in organizations at various levels. However, limited research has been carried out where the process of unlearning has been reflected in different organizational settings, and relatedly, fewer seminal works, compared to organizational learning and organizational change ones, remained acknowledged. As a result, lack of theoretical and empirical studies left the domain equivocal, restricted and under-researched, with a fragmented understanding of unlearning (Hislop et al., 2014, Klammer and Gueldenburg, 2018).

In drive to enhance this discussion on unlearning, this paper aims to portray the overall picture in the relevant literature and intends to emphasize the role of unlearning both in organizational learning and organizational change processes in organizations. It provides a range of definitions to develop the limited understanding of unlearning in management practices, and examines models, frameworks and ideas to clarify the confusions in literature. Furthermore, it proposes a framework to broaden the notion of unlearning in management practices and presents a research agenda that will guide both scholars and practitioners to rethink the phases of learning and change in organizational settings from an "unlearning" perspective.

\section{LITERATURE REVIEW}

\subsection{Defining Unlearning}

While introducing the notion of unlearning, it is crucial to provide a clear definition at the very beginning. Otherwise, related perspectives might remain vague; similarly, the way unlearning is presented might sound superficial, as the definition of unlearning is to be taken for granted, yet remaining ambiguous. Likewise, in advance, it should be clarified in proposed models, frameworks, "what unlearning is not"; like that unlearning is not simply forgetting, or that it is not an "unintended" or a "negative" process that organizations, individuals, groups avoid. On the other hand, it might be erroneous to presume that every organization (and individual or group) follows a similar route in the process of unlearning or apply unlearning in the same manner, which in fact reflects a wide range of possibilities when compared to learning. Therefore, a variety of definitions should also be added, like contextual definitions, in order to elucidate how unlearning is offered as an alternative idea or a new way of managing problems, learning, change etc. in organizational settings.

In management literature, trends in defining the notion of unlearning follow a similar route. The most referenced definition of unlearning comes from Hedberg (1981). He defines unlearning as 'a process through which learners discard knowledge' (p.18). Whilst this definition remains as a starting point, the following ones reflect a parallel understanding with further details. For example, Akgün et al. (2002) state that unlearning is 'the process of reducing or eliminating pre-existing knowledge or habits' (p.60). The authors broaden their definition to an operational one and propose that unlearning is 'changing the organizational beliefs, norms, values, procedures, behavioural routines, and physical artifacts' (p.60). They suggest that the distinct characteristic of unlearning is memory eliminating. Whilst Akgün et al. (2003) provide similar definitions, they place unlearning in their socio-cognitive framework of organizational learning. From a widened understanding, according to Akgün et al. (2007), unlearning is 'eliminating memory via disconfirmation, the disassembly of the connections and mechanisms of memory, and/or changing how memory is manifested' (p.797).

Easterby-Smith and Lyles (2011) differentiate the two notions, organizational forgetting and unlearning, and note that 'Although both terms refer to the loss of organizational knowledge, the difference is that unlearning refers to deliberate attempts to dispose of unwanted knowledge, whereas forgetting refers to a loss of knowledge that is not necessarily planned or intended' (p.311). Tsang and Zahra (2008), in their seminal paper list various, yet homogeneous definitions of organizational unlearning previously published in relevant literature and provide their definition of unlearning as 'the discarding of old routines to make way for new ones, if any' (p.1437). Hislop et al. (2014) summarize definitions in literature in terms of individual, team and organizational unlearning, and from an individualistic perspective, define unlearning as 'a distinctive type of learning, involving a conscious decision to give up knowledge, value or behaviours' (p.556). In our work, we consider unlearning to occur at individual, group and organizational levels, and in a general sense, define unlearning as 'the consious process through which old routines, behaviours, values and obsolete knowledge are discarded, where necessary'.

\subsection{Unlearning within Organizational Learning and Organizational Change}

Literature on organizational learning and change have quite often focused on ideas of adding something new to the individual and/or organizational capacity that increases the amount of skills and knowledge that might not necessarily change the current practice. Accordingly, reframing and/or removing old, and outdated perhaps, ideas, skills and processes have been somehow disregarded, and within the management literature, arguments/notions regarding these issues, like "unlearning" have been considered as controversial. For example, Prahalad and Bettis (1996) argue that: 'If organizational learning means changing an organization's dominant logics, it calls for unlearning of the old [...] However [...] little is known about how an organization's cognitive structures really would be changed. This means that the discussion is only speculative' (quoted in Lähteenmäki et al., 2001: 120). Or from another perspective, while considering unlearning as crucial in unpredictable environments, Gustavsson (2001) discusses the nature of unlearning and questions its occurrence in organizations, as little is known about how it takes place processwise.

However, there have been scholars that emphasized the role and importance of unlearning in their research, directly or indirectly through utilizing different wordings whilst conceptualizing the process of organizational learning. For example, Piaget (1968) defines learning as 'a continuous genesis, a process of creation and recreation, where gestalts and logical structures are added or deleted from memory over time' (quoted in Hedberg, 1981: 4). Thus, whilst Prahalad and Bettis (1996) claim that learning facilitates the process of adding a new logic to the organization and does not essentially require unlearning, Piaget (1968) considers learning as a process of learning, unlearning and relearning.

In terms of long term survival and managing change or chaotic times within organizations; Hedberg (1981) underlines the role of unlearning in making ways for new responses and stresses the need for a balance between learning and unlearning abilities in organizations. In parallel, 
he emphasizes the role of unlearning and reframing that 'can enable an organization to move between environments' (p.10). Whereas Easterby-Smith (1997) mentions that organization's ability to unlearn might be a first-aid tool in times of rapid environmental changes, Gustavsson (2003) draws attention to the necessity to unlearn mental models both for individuals and organizations so as to conform to the discontinuous nature of developments in today's world and to move beyond what's already known. In a similar perspective, Hislop et al. (2014) emphasize that 'the ability of people or organizations to unlearn established knowledge, behaviours, or values can be a significant catalyst to and facilitator of change' (p.541) and considers unlearning as "a key factor" for effective implementation of organizational change.

Recently, types of unlearning, its stages, types etc. have also been discussed in literature. For example, Akgün et al. (2007), depending on the rate of changes in routines and in beliefs, categorize organizational unlearning as "formative, reinventive, operative and adjustive". Authors point out that unlearning 'catalyzes organizational learning process to foster a dynamic learning process, provides a platform for shifting single-loop learning to double-loop learning and connects organizational learning and organizational change processes' (p.806). CegarraNavarro and Wensley (2019) introduce the concept of "intentional and accidental unlearning" and provide their unlearning cycle, emphasizing the processes occurring at individual, group and organizational levels.

Starbuck (2017) elaborates on the stages of unlearning and concludes that while unlearning might not be as "inevitable" in organizational settings, it is for sure a crucial experience for organizations trying to overcome serious crises. While, in a similar manner, in her interview with William H. Starbuck, Nguyen (2017) highlights the crucial role of unlearning within the processes of organizational learning and adaptation, she points out the difference between individual behavior and organizational behavior in the process of unlearning. Tsang and Zahra (2008) discuss the necessity of separating individual and organizational unlearning. Authors consider learning and unlearning as types of organizational change, associate unlearning with relearning and draw attention to the interplay between organizational learning and unlearning. Moreover, Tsang (2017) puts a remark on the "intrinsic connection" between the studies of organizational unlearning and learning organization, and revises his definition of a learning organization as 'a learning organization is one which is good at both organizational learning and unlearning' (p. 46).

\section{A FRAMEWORK FOR CONSIDERING UNLEARNING IN ORGANIZATIONS}

Literature on unlearning in organization studies has evolved and the number of papers on unlearning has increased within the last decades (Nguyen, 2017). Yet, there has been limited interest, compared to organizational learning and change, on unlearning and few empirical studies focused on the nature of the notion, restricting theory development (Tsang and Zahra, 2008) and leaving existing organizational theories of unlearning incomplete and untested. Similary, dimensions and levels of organizational unlearning have not been widely acknowledged, and conceptualization and operationalization of the notion have not been researched in detail (Akgün et al., 2007).

Based on the relevant literature review and the undiscovered gaps in the field, we propose the below framework to build a widened and a clearer understanding of unlearning in organizations, mainly in learning and change processes in organizational settings. The framework, from a three level perspective, individual, group and organizational, intends to find answers to the questions hereafter through further empiricial research; How does unlearning occur in organizations? How do organizations unlearn? Or do they have to? Thus, what is the purpose of unlearning? Is organizational unlearning the sum of individual/group unlearning? Is it just the elimination of processes, explicit/tacit knowledge that was transferred to current technologies in organizational structures and/or settings? What are the advantages if an organization develops itself through unlearning? In real life, are there organizations effectively applying unlearning processes in their actions/strategies? If yes, how do they manage the process? If any, what is the role of unlearning in their change processes and learning activities?

Figure 1: Proposed Framework

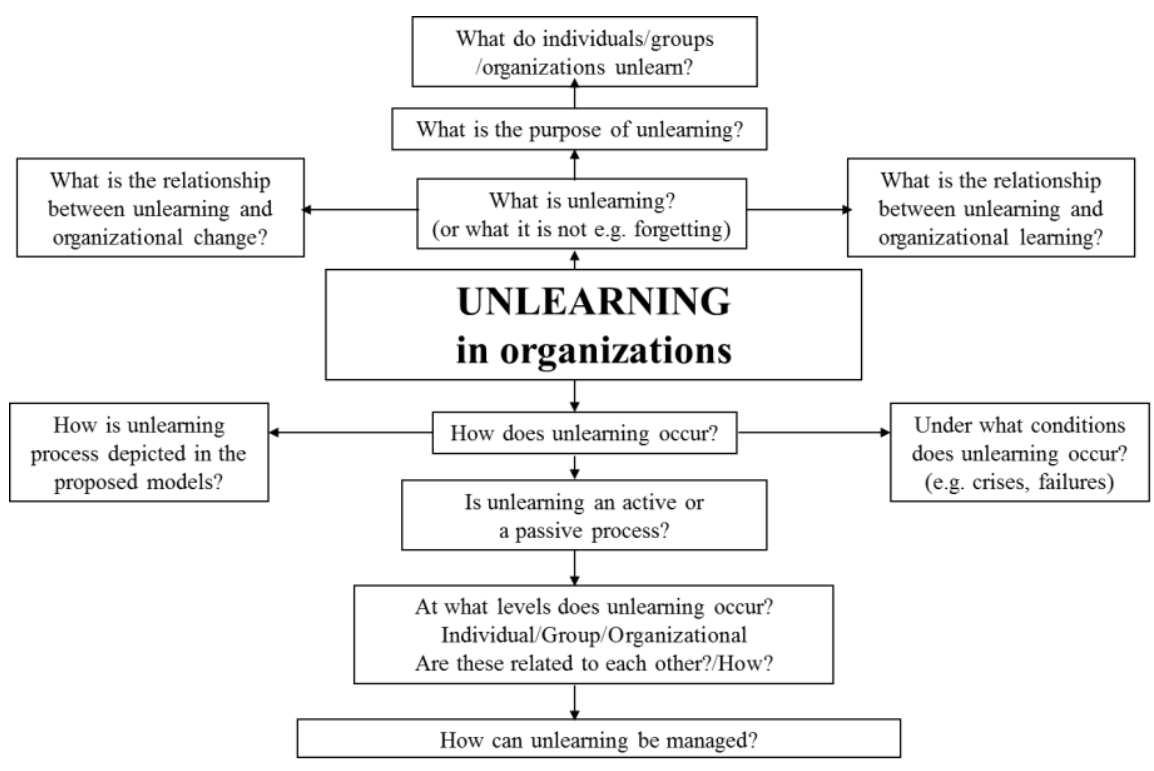


Considering this framework as a guide in our research, we hereby plan to investigate the two propositions below;

Proposition 1. For unlearning to happen in organizational settings, it should actively occur at individual, group and organizational levels.

Proposition 2. Unlearning will ensure organizational adaptation through organizational learning and organizational change in turbulent times.

We intend to analyze these propositions through longitidunal and in-depth qualitative research within different contexts yet having similar dynamic nature of unlearning existence in their organizational settings.

\section{CONCLUSION}

In this paper, we intended to summarize the main ideas on unlearning in management literature and tried to provide an enriched understanding of what "unlearning means" for organizations at individual, group and organizational level.

The point of departure has mainly been Hebderg's (1981) article named 'How organizations learn and unlearn'. Based on his ideas, our purpose was to elucidate the concept of unlearning through pertinent perspectives. In this sense, we elaborated on models, frameworks and ideas to capture the shared understandings and conflicts on the notion within the past four decades. Accordingly, we presented how unlearning has been considered in learning and change literature as a distinct view, proposition or as a model.

While there has been an increased amount of academic work in the literature, little research, mainly empirical, has been carried out where the process of unlearning has been reflected in different organizational settings. Accordingly, current knowledge in organizational studies restricts a detailed understanding of unlearning and lack of empirical studies leaves the territory under-researched and blurred.

Through the framework proposed above and future research in parallel, we aim to capture a widened understanding of unlearning in literature and intend to construct a new perspective in management practices, mainly in organizational learning and change processes, both for scholars and practitioners.

\section{REFERENCES}

Akgün, A. E., Lynn, G. S. \& Reilly, R. (2002). Multi-dimensionality of learning in new product development teams. European Journal of Innovation Management, 5(2), 57-72. DOI: 10.1108/14601060210428168

Akgün, A. E., Lynn, G. S. \& Byrne, J. C. (2003). Organizational learning: a socio-cognitive framework. Human Relations, 56(7), 839-868. DOI: $10.1177 / 00187267030567004$

Akgün A. E., Byrne J. C., Lynn G. S. \& Keskin H. (2007). Organizational unlearning as changes in beliefs and routines in organizations. Journal of Organizational Change Management, 20(6), 794-812. DOI: 10.1108/09534810710831028

Becker, K. (2018). Organizational unlearning: time to expand our horizons? The Learning Organization, 25(3), 180-189. DOI: 10.1108/TLO-102017-0095

Cegarra-Navarro, J.G. \& Wensley, A. (2019). Promoting intentional unlearning through an unlearning cycle. Journal of Organizational Change Management, 32(1), 67-79. DOI: 10.1108/JOCM-04-2018-0107

Easterby-Smith, M. (1997). Disciplines of organizational learning: contributions and critiques. Human Relations, 50(9), 1085-1113. DOI: 10.1023/A:1016957817718

Easterby-Smith, M. \& Lyles, M. A. (2011). In Praise of Organizational Forgetting. Journal of Management Inquiry, 20(3), 311-316. DOI: $10.1177 / 1056492611408508$

Fiol, C. M. \& Lyles, M. A. (1985). Organizational learning. The Academy of Management Review, 10(4), 803-813. DOI: 10.2307/258048

Gustavsson, B. (2001). Power over meaning: whither human values? In S.K. Chakraborty (Ed.), Management of Power - Ethical and Values Aspects (pp. 339-358). Oxford University Press, Dehli.

Gustavsson, B. (2003). The transcendent character of the company. International Journal of Human Resource Development and Management, 3(1), 17-28. DOI: 10.1504/IJHRDM.2003.001042

Hedberg, B. (1981). How organizations learn and unlearn. In P. C. Nystrom \& W. H. Starbuck (Eds.), Handbook of Organizational Design. London (pp.3-27). Cambridge University Press.

Hislop, D., Bosley, S., Coombs, C.R. \& Holland, J. (2014). The process of individual unlearning: a neglected topic in an under-researched field. Management Learning, 45(5), 540-56. DOI: 10.1177/1350507613486423

Klammer, A. \& Gueldenberg, S. (2018). Unlearning and forgetting in organizations: a systematic review of literature. Journal of Knowledge Management, 23(5), 860-888. DOI: 10.1108/JKM-05-2018-0277

Klammer, A., Grisold, T. \& Gueldenberg, S. (2019). Introducing a 'stop-doing' culture: how to free your organization from rigidity. Business Horizons, 62 (4), 451-458. DOI: 10.1016/j.bushor.2019.03.002 
Lähteenmäki, S., Toivonen, J. \& Mattila, M. (2001). Critical aspects of organizational learning research and proposals for its measurement. British Journal of Management, 12(2), 113-129. DOI: 10.1111/1467-8551.00189

Nguyen, N. (2017). The journey of organizational unlearning: a conversation with William H. Starbuck. The Learning Organization, 24(1), 5866. DOI: 10.1108/TLO-11-2016-0076

Nystrom, P.C. \& Starbuck, W.H. (1984). To avoid organizational crises, unlearn. Organizational Dynamics, 12 (4), 53-65. DOI: 10.1016/00902616(84)90011-1

Piaget, J. (1968). Le Structuralisme. Paris: Presses Universitaires de France.

Prahalad, C. K. \& Bettis, R. (1996). The dominant logic - a new linkage between diversity and performance. In K. Starkey (Ed.), How Organizations Learn (pp.100-122). London: International Thomson Business Press.

Sinkula, M. J. (2002). Market-based success, organizational routines, and unlearning. The Journal of Business Marketing, 17(4), 253-269. DOI: $10.1108 / 08858620210431660$

Starbuck, W.H. (2017). Organizational learning and unlearning. The Learning Organization, 24(1), 30-38. DOI: 10.1108/TLO-11-2016-0073

Tsang, E.W.K. \& Zahra, S.A. (2008). Organizational unlearning. Human Relations, 61(10), 1435-1462. DOI: 10.1177/0018726708095710

Tsang, E.W.K. (2017). How the concept of organizational unlearning contributes to studies of learning organizations: a personal reflection. The Learning Organization, 24(1), 39-48. DOI: 10.1108/TLO-10-2016-0064 